\title{
Determination of leg injury criteria subjected to frontal impacts
}

\begin{abstract}
The leg injury criteria subjected to frontal impact is presented and discussed. The aim is to analyze the effect of steel material of bumper shell on pedestrian leg injury criteria of front bumper system. The front bumper beam is made of mild steel and characterized by impact modeling using LS-DYNA V971, according to United States New Car Assessment Program (US-NCAP) frontal impact velocity and based on European Enhanced Vehicle-safety Committee. The most important variable of this structure are mass, material, internal energy, and Leg Injury Criterion (LIC). In order to evaluate the protective performance of the baseline hood, the Finite Element Models (FEM) of legform of an adult pedestrian is used. The result shows that the acceleration of $91.5 \mathrm{~g}$, shear displacement of $4.2 \mathrm{~mm}$ and bending angle of 12.0ęgraphs are performing below the danger limit. The reason found to be there were no contact between the front bumper beam and the legform, so that the injury is less. This is shows that the clearance between the bumper shell and front bumper beam are sufficient.
\end{abstract}

Keyword: Front bumper system; Leg injury criteria; Steel 